\title{
Chemotactic Process
}

National Cancer Institute

\section{Source}

National Cancer Institute. Chemotactic Process. NCI Thesaurus. Code C16422.

The characteristic directional movement or orientation of an org anism or cell along a chemical concentration gradient either toward or away from the chemical stimulus. 